\title{
CONSIDERAÇÕES SOBRE O RACISMO EM LIMA BARRETO: UMA ANÁLISE SOCIOLÓGICA DO CONTO “O PECADO” 1
}

\author{
ARTIGO ORIGINAL \\ MANSANO, Silvana ${ }^{2}$ \\ MANSANO, Amauri ${ }^{3}$
}

TOTTI, Marcelo Augusto ${ }^{4}$

MANSANO, Silvana. MANSANO, Amauri. TOTTI, Marcelo Augusto. Considerações sobre o racismo em Lima Barreto: Uma análise sociológica do conto "o pecado". Revista Científica Multidisciplinar Núcleo do Conhecimento. Ano 05, Ed. 09, Vol. 07, pp. 05-20. Setembro de 2020. ISSN: 2448-0959, Link de acesso: https://www.nucleodoconhecimento.com.br/sociologia/analise-sociologica

${ }^{1}$ O presente trabalho foi realizado com apoio da Coordenação de Aperfeiçoamento de Pessoal de Nível Superior - Brasil (CAPES) - Código de Financiamento 001. (This study was financed in part by the Coordenação de Aperfeiçoamento de Pessoal de Nível Superior - Brasil (CAPES) - Finance Code 001).

2 Mestranda do Programa de Pós-Graduação em Ciências Sociais da Faculdade de Filosofia e Ciências (FFC), da Universidade Estadual Paulista "Júlio de Mesquita Filho" (UNESP), Campus de Marília-SP; bacharela em Ciências Sociais pela Faculdade de Filosofia e Ciências (FFC), da Universidade Estadual Paulista "Júlio de Mesquita Filho" (UNESP), Campus de Marília-SP; bacharela em Direito pela Pontifícia Universidade Católica de Campinas - PUCCAMP (OAB/SP: 181.564).

${ }^{3}$ Bacharel em Direito pela Pontifícia Universidade Católica de São Paulo - PUC-SP.

${ }^{4}$ Orientador. Doutorado em Educação Escolar. Mestrado em Educação Escolar. Graduação em Ciências Sociais. 


\section{RESUMO}

Tendo como base de análise o conto O Pecado, mostraremos como o escritor Lima Barreto, grande pensador social do seu tempo, elaborou e demonstrou o racismo, representando uma voz dissonante que recusou a se calar, denunciando negligências e injustiças cometidas contra a parte mais vulnerável da sociedade. Como autor de um período turbulento de transição, escreveu contra a cristalização de preconceitos advindos da monarquia. Para fazermos uma análise sociológica do conto, usaremos o método proposto por Candido (2006). Sevcenko (1995) nos mostra o momento turbulento pelo qual passava o país na Primeira República (1890-1930) e como a literatura se torna fonte importante de informação. No tocante ao racismo, veremos com Schwarcz (1993) como as teorias raciais foram implantadas com o apoio do Estado; com Foucault (1999) como o racismo se torna aparelho opressor do Estado. Para nos dar respostas sobre como ocorre a morte da população negra, trouxemos Sémelin (2009) e Agamben (2002). Com isso, mostraremos de que modo Lima Barreto, como grande pensador social, deixa evidente a crítica que pretende fazer.

Palavras-chave: Lima Barreto, racismo, pensamento social.

\section{INTRODUÇÃO}

Os estudos sobre o escritor Afonso Henriques de Lima Barreto (1881-1922), até os anos de 1950, quase sempre ficaram marcados por sua vida pessoal que, para a maior parte dos críticos da época, superou suas obras. Salvo raras exceções, o escritor sempre se sentiu à margem do círculo de escritores do seu tempo, já que se rebelou contra ditames literários, contra o Estado, contra políticos e empresários, contra 0 preconceito e muitos outros assuntos que, naquele momento, não eram discutidos.

Foi somente com uma grande e vigorosa biografia, feita por Francisco de Assis Barbosa, em 1952, que outro olhar se lançou sobre o escritor. A partir desse episódio suas obras, até então rejeitadas por inúmeras editoras foram, finalmente, lançadas em 1953. As reedições de todas as obras vieram na sequência, em 1956. Isso deu estofo para que o escritor, proscrito por tantas décadas, ganhasse novos estudos 
literários que lançaram luz sobre o período da Primeira República e as reflexões sociais que Lima fazia sobre seu entorno, tendo como pano de fundo a cidade do Rio de Janeiro, que passava por imensas transformações, rumo ao encontro da modernidade.[5]

O fato do escritor se inserir num período literário de grande transição - Romantismo, Naturalismo, Simbolismo e Parnasianismo -, causou rejeição por boa parte dos leitores, ainda sedentos de histórias que Ihes transportassem para um mundo de sonhos. E Lima Barreto não oferecia isso, somente a crueza do cotidiano, o humor ácido, a ironia jocosa sobre muitos aspectos e comportamentos da sociedade, a crítica contundente às omissões do Estado, a inserção humanizada de personagens desvalidos e o combate contra os poderosos. Isso the causou imensos prejuízos sociais, sendo estigmatizado com rótulos como "ressentido", "louco" e "maldito"; também sofreu prejuízos financeiros, já que para ter publicados seus livros encontrou grandes dificuldades (MANSANO, 2009)

Mesmo com muitas dificuldades, advindas das péssimas condições financeiras, Lima Barreto prosseguiu denunciando e analisando as mazelas da sociedade do período em que viveu. Foi um crítico contundente da sua época, indo de encontro aos interesses de uma sociedade aristocrática que fazia de tudo para manter os privilégios de outrora, sendo um dos poucos brasileiros que compreendeu as transformações políticas e sociais do seu tempo. Segundo (PRADO, 1989), o escritor teceu inúmeras análises sobre a conjuntura nacional e, inclusive, internacional. Foi um dos poucos brasileiros, por exemplo, a entender a importância e o impacto que teria a Primeira Guerra Mundial no Brasil.

O biógrafo Francisco de Assis Barbosa (2012), diz que o escritor trabalhou de 1900 até sua morte, em 1922 como colaborador em inúmeros jornais e revistas da época, sempre fazendo as mais variadas análises, o que acentuou sua verve de grande observador do cotidiano e das transformações que ocorriam no Brasil da Primeira República. Lima Barreto inovará com sua escrita coloquial e acessível, sendo precursor do Modernismo no país, traquejo adquirido também dessa prática jornalística. Com isso, irá tecer análises sociológicas sobre as galopantes 
transformações que vieram com a modernidade, além das relações sociais neste novo cenário.

O conto O Pecado foi escrito por Lima Barreto como uma forma de denunciar o racismo que ele combateu de modo veemente, mas sem deixar de lado uma de suas características: a ironia. A história bem humorada e curta, versa sobre o racismo e denuncia as dificuldades de inserção do negro na nova conformação social, não importando quais fossem as qualidades, as habilidades, a retidão de caráter e os esforços empreendidos: ao negro restava apenas a impossibilidade de viver com dignidade e ser aceito pela sociedade.

Tendo como suporte metodológico Antonio Candido (2006), a intenção é colaborar para o entendimento de como se processa a literatura de Lima Barreto, como o escritor captura e interpreta os fenômenos sociais. Assim, o objetivo é verificar o que Candido propõe: a influência do meio social sobre a arte e também o contrário, a influência da arte sobre o meio social. Segundo o estudioso, para entendermos os fenômenos histórico-culturais de um povo e, ao mesmo tempo, fazermos uma leitura sociológica da obra, torna-se importante compreender o tripé obra-autor-estrutura social. (2006)

Seguindo o percurso proposto por Candido (2006), veremos a vida do escritor, em que a obra mais importante é a de Francisco Assis Barbosa (2012). Na sequência, após a exposição do conto, faremos um panorama dos problemas sociais da Primeira República (1890-1930), sendo de grande importância Nicolau Sevcenko (1995), que nos fala sobre como a literatura se processa em Lima Barreto; Lília Schwarcz (1993), que explica como as teorias raciais foram construídas para justificar a ausência do Estado na inserção do negro após a abolição. Com Foucault (1999) veremos como o racismo se torna aparelho opressor do Estado. Para nos dar respostas sobre como ocorre a morte da população negra, trouxemos Sémelin (2009) e Agamben (2002).

O objetivo deste trabalho, por fim, é mostrar que Lima Barreto foi um dos primeiros pensadores sociais do Brasil, no que tange à temática negra. Trouxe à reflexão do leitor, de forma crua, um problema social que era comum no início do Século XX, mas 
que pensadores, sociólogos e escritores do período ainda insistiam em não mostrar de forma tão contundente.

\section{VIDA E OBRA}

A vida do escritor Lima Barreto foi, sem dúvida alguma, repleta dos mais dolorosos dissabores desde a mais tenra infância. Eivada de interrupções em toda curta trajetória de 41 anos, isso para alguns incomoda e faz turvar a análise de sua grandeza. Ao ler sua biografia, não fica fácil se abstrair da sua vida dolorosa para se focar somente nas obras, pois são complementares entre si. Para muitos críticos, isso é um demérito. Mas há que se entender que o escritor também leva para suas obras parte de sua vida e que, entre biografia e o que se escreve, pode, sim, haver essa ponte sem que se ignore o talento que, no caso de Lima, é resplandecente. Então a sua dor é a sua obra, e vice-versa. (MANSANO, 2017)

Afonso Henriques de Lima Barreto nasce exatamente sete anos antes da abolição da escravatura, na emblemática sexta-feira do dia 13 de maio de 1881. É com seu maior biógrafo, Francisco de Assis Barbosa (2012), que encontramos importantes detalhes da vida do escritor. O biógrafo resgatará escritos inéditos, além dos diários que resultaram em obras importantes - Diário íntimo e Cemitério dos vivos - que descortinam os mais profundos pensamentos do autor, suas inquietações, desgostos e anseios.

Neto de escravos, filho de um tipógrafo e uma professora, ficará órfão de mãe aos 7 anos. Tenho como padrinho o Visconde de Ouro Preto, chegará a cursar engenharia na Escola Politécnica, tendo que abandoná-la, pois seu pai adoece e, ainda muito jovem, o escritor se tornará arrimo de família. Prestará concurso e trabalhará como amanuense, mas necessitava completar a renda, passando então a escrever para periódicos de revistas e jornais. A relação com o jornalismo será fecunda, gerando inúmeros artigos e impelindo-o a escrever seus romances

Barbosa (2012) diz que primeiro livro do escritor será Recordações do escrivão Isaías Caminha, de 1909, um Roman à cléf que o levaria à ruína pessoal e financeira, já que 
ironizava diversas pessoas facilmente reconhecíveis na obra, e o sitiaria dos círculos sociais e editoriais. Na sequência, ainda segundo seu biógrafo Assis Barbosa, Lima tem seu período mais produtivo, escrevendo os contos Califórnia, de novembro de 1910; depois escreveria seu maior e mais aclamado romance, Triste fim de Policarpo Quaresma, entre janeiro e março de 1911, mas que só foi lançado em 1915, com subsídios do próprio autor, já que todas as editoras Ihe fecharam as portas. E em abril lança outro conto, O homem que sabia javanês. Em 1912 ainda lança As aventuras do Dr. Bogoloff. Com imensos conflitos pessoais, sociais e financeiros, data dessa época, seus primeiros problemas relacionados ao abuso de álcool. Em 1914 será internado pela primeira vez, quando o escritor está com 33 anos.

O escritor colaborou com inúmeros jornais, revistas e periódicos, escrevendo centenas de crônicas (2012), sendo que 1907 fundará a Revista Floreal, junto com os colegas anarquistas, grandes expoentes da época: Domingos Ribeiro, Fábio Luz, Curvelo de Mendonça e Elísio de Carvalho. Data deste período seu contato mais intenso com as ideias anarquistas e libertárias que o acompanharão por toda a vida. Politicamente, terá sempre um posicionalmente rebelde, de rompimento com o sistema posto naquele momento, sendo um grande crítico do patriotismo exacerbado. (2012)

Lima Barreto ainda escreverá Numa e Ninfa, de 1915, onde acentua o forte teor panfletário; conclui em 1919 Vida e morte de M. J. Gonzaga de Sá, que havia começado a escrever por volta de 1905; também lança Histórias e sonhos em 1920.

O conto, anexado ao final deste trabalho, foi publicado pela primeira vez em 1924, na Revista Souza Cruz - portanto, postumamente. Não localizamos referências que nos dessem a data precisa de quando teria sido escrito.

O escritor irá falecer em 1ํ. de novembro de 1922. No dia 3 de novembro de 1922, apenas 48 horas depois de sua morte, o pai João Henriques também vem a falecer. Pai e filho são sepultados no cemitério São João Batista, no bairro do Botafogo. 
Algumas obras de Lima Barreto só seriam publicadas postumamente, muitas delas devido ao empenho do biógrafo Assis Barbosa, do contrário poderiam ter sido perdidas. Entre as obras póstumas estão Os Bruzundangas e Bagatelas, em 1923; Diário íntimo, Feiras e Mafuás e Marginália, todas publicadas em 1953. Em 1956 seriam publicadas as obras póstumas Cemitério dos Vivos (obra inacabada), Coisas do Reino de Jambom, Impressões de leitura e Correspondências (2 volumes), além da reedição completa das obras anteriores.

\section{O CONTO O PECADO}

O conto O Pecado escrito por Lima Barreto é curto, porém impactante, e versa sobre uma pessoa - P. L. C. - que morre e sua "alma", chegando ao céu, é interpelada por São Pedro, o porteiro responsável por definir quem fica ao lado do trono celestial e quem vai para o purgatório. Ao ler o histórico de referida "alma", com a ajuda do guarda-livros, conclui-se que ela é casta, honesta, bondosa e, portanto, se encontra apta e digna de estar ao lado do trono celestial. Mas, São Pedro insiste para o guardalivros rever a análise, e descobre-se que um detalhe importante havia passado despercebido pelo Santo: no item observação estava escrito que a "alma" era negra. E foi esse detalhe que selou o destino final da alma de P. L. C., o de ir para o purgatório.

O Purgatório, concepção da Igreja Católica, irá surgir na modernidade, como forma de justiça penitencial: "Os que morrem carregados apenas com pecados veniais passarão um tempo mais ou menos longo de expiação num lugar novo, o Purgatório, que irão deixar depois de purificados, purgados, em troca da vida eterna, do Paraíso, o mais tardar no momento do Juízo Final". (LE GOFF apud COSTA, 2011, p. 2279). Então, neste caso, o escritor nos mostra que o purgatório é o lugar da desumanização completa a que estava submetido o negro.

Lima Barreto usou a literatura e o ofício de jornalista como ferramentas para denunciar o racismo em uma sociedade que se dizia estar rumo ao "progresso" e à "modernização", mas que impossibilitava o negro de ser cidadão. Não é possível deslocar Lima não apenas do seu entorno social, mas também da época em que viveu, 
repleta de transformações por toda parte. Uma importante transformação se refere ao pensamento social que aflorava na época, com bases nas teorias raciais. Com o apoio do Estado, os pensadores selecionados para pensar e refletir sobre os dilemas de um país jovem, recém saído do regime escravocrata e da monarquia, fazem parte da continuação da cristalização de preconceitos.

Lilia Schwarcz (1993), que analisa o período de 1870 a 1930, diz que os "homens das ciências" selecionados para pensar o Brasil, tenderam a adotar modelos evolucionistas e social-darwinistas, observando que não houve uma confluência aleatória, mas selecionada para atender ao pensamento conservador. E é dessa forma que ela explica como, por exemplo, o argumento racial foi política e historicamente construído, assim como o conceito de "raça" que, além de sua interpretação biológica, acabou recebendo uma interpretação racial. Desse modo, as teorias raciais de então se transformam em um argumento de sucesso para o estabelecimento de critérios diferenciadores de cidadania, bem como meio de pensar um projeto civilizatório para o país, além de legitimarem as diferenças sociais da antiga ordem escravocrata. O que se observa, diz a autora, é que as teorias adotadas no Brasil não foram aleatórias e nem fruto da sorte, mas sim introduzidas de forma crítica e seletiva. E dessa forma passaram a ser utilizadas como instrumento de respaldo conservador e autoritário, reafirmando as fortes hierarquias sociais que já existiam no Brasil. (SCHWARCZ, 1993)

O pensamento social no final do Século XIX ainda está se desenvolvendo. No artigo A Sociologia do Brasil, Antonio Candido (2006b) trabalha a partir de uma divisão temporal em dois períodos, com uma fase transitória entre eles. Sua divisão distingue nitidamente a evolução da sociologia através da contribuição de vários autores. Candido mostra a contribuição da literatura para o desenvolvimento da análise da sociedade, sendo a principal matriz que alimentou os estudos sobre a sociedade. A contribuição da literatura trouxe características próprias no desenvolvimento da sociologia no Brasil, pois surge com ela a necessidade de compreender a nossa realidade social e criar nossa própria evolução mental. (2006b). 
Nicolau Sevcenko (1995) lançará mão de dois escritores - Lima Barreto e Euclides da Cunha - para tecer análises sobre como a literatura se torna fonte importante de compreensão da Primeira República. Para o estudioso, o início da República é marcado por sucessivas crises e que uma filtragem dos elementos não necessários foi realizada. As mudanças ocorridas na capital do Brasil são forçadas para que se abra o caminho para a modernidade que vem da Europa, em especial da França e da Belle Époque. Ao selecionar dois escritores, o estudioso nos mostra que a literatura surge como contraponto a um pensamento social que foi posto por essa nova República. Para ele a arte é um instrumento eficaz para modificar uma situação, já que sua correta utilização tem um efeito decisivo sobre a comunidade. Assim, a literatura facilita a comunicação entre os homens, sendo ao mesmo tempo um veículo de valores éticos superiores e uma condicionadora de comportamentos. Semelhante a isso em sua grandeza seria a militância. E Lima Barreto nos mostra, com uma literatura social militante, uma voz solitária contra os abusos e injustiças do período. (SEVCENKO, 1995).

O Brasil, inundado de uma imensidão de negros recém libertos, não escolheu a forma inclusiva para essa população, mas a de exclusão, empurrando o problema para os arredores da cidade. E, os pensadores, continuavam a refletir e estudar formas de branquear a população, pois a miscigenação era um erro. Não houve políticas públicas de inclusão social, econômica e cultural desses desvalidos. O encontro com a modernidade fará cintilar diante da aristocracia branca a triunfal saída para os indesejados negros, agora sem serventia: as teorias raciais. (MANSANO, 2017)

Michel Foucault, no livro Em Defesa da Sociedade, diz que o racismo é um elemento de guerra e, se observarmos uma sociedade como era a nossa da Primeira República, fica fácil vislumbrar uma guerra social entre os brancos, que faziam leis e ditavam as normais sociais, contra os negros, sem poder algum, já que houve uma continuidade da escravidão e eles foram oprimidos e alijados. E assim a biopolítica, com suas novas tecnologias de poder, tentará "fazer viver e deixar". (1999) 
As teorias raciais que emergem em todo mundo, respaldam a superioridade de algumas raças em detrimento de outras. $\mathrm{O}$ autor diz que o darwinismo deu uma roupagem científica ao racismo.

Com efeito, o que é o racismo? É, primeiro, o meio de introduzir afinal, nesse domínio da vida de que o poder se incumbiu, um corte: o corte entre o que deve viver e o que deve morrer. No contínuo biológico da espécie humana, o aparecimento das raças, a distinção das raças, a hierarquia das raças, a qualificação de certas raças como boas e de outras, ao contrário, como inferiores, tudo isso vai ser uma maneira de fragmentar esse campo biológico de que o poder se incumbiu; uma maneira de defasar, no interior da população, uns grupos em relação aos outros. Em resumo, de estabelecer uma cesura que será do tipo biológico no interior de um domínio considerado como sendo precisamente um domínio biológico. Isso vai permitir ao poder tratar uma população como uma mistura de raças ou, mais exatamente, tratar a espécie, subdividir a espécie de que ele se incumbiu em subgrupos que serão, precisamente, raças. Essa é a primeira função do racismo: fragmentar, fazer cesuras no interior desse contínuo biológico a que se dirige o biopoder. (FOUCAULT, 1999, p. 305)

Para que o Estado empreenda o racismo como forma de fragmentação social e o fortalecimento de uma raça em detrimento da outra, precisará da ajuda valiosa da medicina, que entrará para dar respaldo científico aos objetivos do Estado:

E vocês compreendem então, nessas condições, por que e como um saber técnico como a medicina, ou melhor, o conjunto constituído por medicina e higiene, vai ser no século XIX um elemento, não o mais importante, mas aquele cuja importância será considerável dado o vínculo que estabelece entre as influencias cientificas sobre os processos biológicos e orgânicos (isto é, sobre a população e sobre o corpo) e, ao mesmo tempo, na medida em que a medicina vai ser uma técnica política de intervenção, com efeitos de poder próprios. A medicina é um saber-poder que incide ao mesmo tempo sobre o corpo e sobre a população, sobre o organismo e sobre os processos biológicos e que vai, portanto, ter efeitos disciplinares e efeitos regulamentadores. (FOUCAULT, 1999, pp.301-302)

Voltando ao período em que o conto foi escrito, destaca-se que na Primeira República despontavam estudiosos que vinham com pensamentos sociais eivados de preocupações com a mestiçagem que avançava Brasil afora. E, indo ao encontro do que disse Foucault logo acima, essas teorias foram reforçadas por médicos, 
devidamente selecionados para essa função de diminuir a raça negra, além de juristas e engenheiros. O artigo de Candido (2006b) já mencionava a influência dos médicos na produção de teorias raciais aqui no Brasil.

No Brasil tivemos uma intensa articulação de médicos que escreveriam no mesmo sentido de reforço às teorias raciais. O médico e antropólogo Baptista de Lacerda apresentou-se no I Congresso Internacional das Raças, que foi realizado em Londres em 1911, a tese em que concluía que a raça negra seria extinta no país em cem anos, permanecendo pouquíssima mestiçagem (Sobre os mestiços do Brasil). Neste artigo o médico defendeu a miscigenação como algo positivo para o Brasil porque estava em franca vantagem a sobreposição dos traços da raça branca sobre as outras - no caso, a negra e a indígena - e, assim, em poucos anos o país deixaria de ter pessoas negras. Outro estudioso que estava no mesmo congresso, o médico Roquette-Pinto, avalizou Baptista e seguiu com igual pensamento de reprovação ao negro e à mestiçagem.

É nesta época também que o médico legista e antropólogo Raymundo Nina Rodrigues lançou o livro Os africanos no Brasil, onde seria ainda mais enfático quanto ao atraso que a mestiçagem e o negro provocariam no Brasil. Ao explicar o critério científico da inferioridade da raça negra diz:

Para a ciência não é esta inferioridade mais do que um fenômeno de ordem perfeitamente natural, produto da marcha desigual do desenvolvimento filogenético da humanidade nas suas diversas divisões e seções. (...) os negros pertencem a outra fase do desenvolvimento intelectual e moral. (NINA RODRIGUES, 1933, p. 12)

Muitos outros médicos e intelectuais empreenderam estudos para respaldar o risco que o Brasil corria com a miscigenação e o negrismo. Lima Barreto estava muito atento a isso, por diversas vezes escreveu, questionou, denunciou e se revoltou contra o racismo. E, em seu diário, já se mostrava temeroso sobre o avanço da eugenia, que alcançaria, inclusive, os judeus.

Vai se estendendo, pelo mundo, a noção de que há algumas raças superiores e umas outras inferiores, e que essa inferioridade, longe de ser transitória, é eterna e intrínseca à própria estrutura de raça. Diz-se 
ainda mais: que as misturas entre essas raças são um vício social, uma praga e não sei que cousa feia mais. Tudo isso se diz em nome da ciência e a coberto da autoridade de sábios alemães. Eu não sei se alguém já observou que o alemão vai tomando, nesta nossa lúcida idade, o prestígio do latim na Idade Média. O que se diz em alemão é verdade transcendente. Por exemplo, se eu dissesse em alemão - o quadrado tem quatro lados - seria uma cousa de um alcance extraordinário, embora no nosso rasteiro português seja uma banalidade e uma quase verdade. E assim a cousa vai se espalhando, graças à fraqueza da crítica das pessoas interessadas, e mais do que à fraqueza, à covardia intelectual de que estamos apossados em face dos grandes nomes da Europa. Urge ver o perigo dessas idéias, para a nossa felicidade individual e para nossa dignidade superior de homens. Atualmente ainda não saíram dos gabinetes e laboratórios, mas, amanhã, espalhar-se-ão, ficarão à mão de políticos, cairão sobre as rudes cabeças da massa, e talvez tenhamos de sofrer matanças, afastamentos humilhantes, e os nossos liberalíssimos tempos verão uns novos judeus. Os séculos que se passaram não tiveram opinião diversa a nosso respeito - é verdade; mas, desprovidas de qualquer base séria, as suas sentenças não ofereciam o mínimo perigo. Era o preconceito; hoje é o conceito. (BARRETO, 1956, p. 16)

Para entendermos esse posicionamento de ter tantos cientistas ao lado do Estado respaldando o racismo, vimos que Jacques Sémelin (2009) discute o "massacre" e tenta compreender $\mathrm{o}$ ato de passagem do "querer" destruir para o de destruir propriamente dito. Para ele, torna-se urgente entender como os poderes estatais, juntamente com o apoio da sociedade em crise, não se contentaram apenas com o controle social ou a expulsão do outro. Buscaram a destruição deste, apoiando-se em retóricas que remetem ao imaginário e ao sagrado, com discursos de purificação e práticas de destruição de todo o corpo social. (2009). Ele diz que o poder estatal se torna coordenador do processo de exclusão do "Outro", de purificação do corpo social. Em suma, o autor busca a compreensão das práticas políticas de "purificação" e de "destruição", que já eram observáveis durante o séc. XIX e, que chegaram ao seu ápice no decorrer do séc. XX. (2009, p. 26).

Já Giorgio Agamben (2002) diz que homo sacer é o ser matável e sacrificável, então, se observarmos as teorias raciais que pregavam o branqueamento e que foram respaldadas pelo Estado, é como se a população negra na Primeira República fosse 
a população sacer, matável, insacrificável, aquela que deve ir para o purgatório. Eis o que diz Agamben:

Se algo caracteriza, portanto, a democracia moderna em relação à clássica, é que ela se apresenta desde o início como uma reivindicação e uma liberação da zoé, que ela procura constantemente transformar a mesma vida nua em forma de vida e de encontrar, por assim dizer, o bíos da zoé. Daí, também, a sua específica aporia, que consiste em querer colocar em jogo a liberdade e a felicidade dos homens no próprio ponto - a "vida nua" - que indicava a sua submissão. Por traz do longo processo antagonístico que leva ao reconhecimento dos direitos e das liberdades formais está, ainda uma vez, o corpo do homem sacro com a seu duplo soberano, sua vida insacrificável e, porém, matável. (AGAMBEN, 2002, p. 17, grifos do autor)

O negro, após a abolição, viveu à margem, na periferia, isolado, sem trabalho certo, sem qualificação - portanto, a morte do negro não é sacrifício, porque para ser sacrificado precisa ser puro. E se, mesmo com tantas adversidades por viver na exceção, o negro ainda tivesse valores nobres, vivido em retidão e sem desvio nenhum, não importa, ele é negro e faz parte da exceção que é matável.

Ao apresentarmos o que pode ter levado Lima Barreto a escrever essa crônica - o racismo que se perpetuava desde a escravidão -, vimos que ele usa a literatura como uma arma, é a sua militância. Como diz Goldman (1967), o artista militante usa a sua arte para, de certa forma, desestruturar as estruturações mentais daquilo que o leitor está habituado para, assim, conduzi-lo a uma participação no processo de transformação da realidade que o cerca. É com esse movimento que se pode promover a estruturação de novas totalidades pessoais e sociais. (GOLDMAN, 1967)

A denúncia feita pelo escritor, além de uma constatação dolorosa que ele mesmo vivenciava, era também um alerta para que essa realidade se transformasse: "[...] a arte como a literatura funcionam em Lima Barreto como um espelho revelador através do qual a obra do artista, ou do poeta, refletindo a natureza do todo, contribuem para que a vida em sociedade se aprimore e harmonize" (PRADO, 1989, p. 72)

Para Nicolau Sevcenko (1995), o estudo da Literatura é capaz de trazer consigo nova possibilidade de análise do passado por meio da fala dos não ajustados socialmente. 
Por ter sido um escritor negro, que viveu no subúrbio toda sua vida e passou por muitas dificuldades financeiras, soube transportar para a ficção uma realidade social que a história oficial do país não estava contemplando. E, foi desta forma, que o escritor deu voz aos que foram excluídos e desumanizados.

\section{CONSIDERAÇÕES FINAIS}

Ao trazermos o conto $O$ Pecado, almejamos problematizar que o doloroso castigo infligido a P. L. C. é o castigo da história de vida dos negros no Brasil - não importa quão bom eles sejam, pois isso não tem nenhuma valia no Estado racista. Vimos, também, que a biopolítica da Primeira República fomentou a fragmentação social trazendo ideias eugenistas como forma de branquear o Brasil e, com isso, fez dos negros a população sacer que pode ser eliminada. Dessa forma, o Estado decide qual vida deve ser vivida e, para isso, usa de meios científicos que venham ao encontro do que deseja.

E o escritor Lima Barreto, sendo negro, pobre e oprimido, sabia perfeitamente que a cor negra era uma moléstia a ser eliminada pelo Estado racista e que haveria um longo caminho de luta intensa pela frente se o negro desejasse ser bíos para impedir o avanço dessa estratégia política do Estado sobre ele.

Lima Barreto, um escritor incompreendido, que teve suas possibilidades de ascensão bloqueadas de todas formas, fez da escrita uma arma de denúncia da situação em que se encontrava o negro na Primeira República - em certa medida, restava o purgatório, aquele espaço nebuloso sem inclusão, cidadania, sem direitos, sem respeito. Não poderia ser massacrado ou sacrificado, mas era um ser matável.

Assim, o conto $O$ Pecado, apesar de curto, mostra de forma contundente o que restou ao negro na nova conformação social após a abolição: que ele continuaria no purgatório civil, sem direitos, sem reconhecimento. Nele, há um angustiante grito de dor de quem tem plena consciência da situação que foi reservada ao negro. 


\section{REFERÊNCIAS}

AGAMBEN, Giorgio. Homo Sacer: o poder do soberano e a vida nua. Belo Horizonte: Ed. UFMG; 2002.

BARRETO, Lima. Contos Completos. Organização e Introdução de Lília Moritz Schwarcz. Disponível em: http://lelivros.love/book/download-contos-completos-delima-barreto-lima-barreto-em-epub-mobi-e-pdf Acessado em 11 de Julho de 2020, $11 \mathrm{~h} 30$.

BARRETO, Afonso Henriques de Lima. Clara dos Anjos. São Paulo: Penguim \& Companhia da Letras, 2016.

BARRETO, Afonso Henriques de Lima. Recordações do Escrivão Isaías Caminha. Rio de Janeiro: Publifolha, 1997

BARRETO, Afonso Henriques de Lima. Diário Íntimo. Ministério da Cultura. Fundação Biblioteca Nacional: Departamento Nacional do Livro. 2006

BARRETO, Afonso Henriques de Lima. Lima Barreto: obra reunida, volume 1. Triste fim de Policarpo Quaresma. Rio de Janeiro, Nova Fronteira, 2018

BARRETO, Afonso Henriques de Lima. 0 cemitério dos vivos: memórias. Prefácio de Eugênio Gomes. São Paulo: Brasiliense, 1956

BARRETO, Afonso Henriques de Lima. Lima Barreto: obra reunida, volume 3. Aventuras do Doutor Bogolóff. Rio de Janeiro, Nova Fronteira, 2018

BARRETO, Afonso Henriques de Lima. Lima Barreto: obra reunida, volume 1 Numa e Ninfa. Rio de Janeiro, Nova Fronteira, 2018

CANDIDO, Antonio. Literatura e Sociedade. Rio de Janeiro: Ouro Sobre Azul, 2006.

CANDIDO, Antonio. A sociologia no Brasil: tempo Social. Revista de sociologia da USP, São Paulo, v. 18, n.1, jun. 2006b. 
COSTA, Milton Carlos. Usura e Purgatório: Jacques Le Goff e a Antropologia do Sagrado Medieval. Disponível em: http://www.cih.uem.br/anais/2011/trabalhos/190.pdf Acessado em: 10 de Julho de 2020, $09 \mathrm{~h} 26$.

FOUCAULT, Michel. Em defesa da sociedade. São Paulo: Martins Fontes, 1999

GOLDMANN, Lucien. O Método Estruturalista Genético na História da Literatura. In: Sociologia do Romance. Tradução de Álvaro Cabral. Rio de Janeiro: Paz e Terra, 1967, p. 204.

LACERDA, João Batista de. ROQUETTE-PINTO, Edgard. Relatório sobre o primeiro congresso internacional das raças. Rio de Janeiro: Museu Nacional, 1912. Disponível em: http://www.scielo.br/pdf/bgoeldi/v7n3/a08v7n3.pdf Acesso em: 27 de Julho de 2020, 15h23.

MANSANO, Silvana. O romance "Clara dos Anjos" de Lima Barreto: um crítica social do Rio de Janeiro na Primeira República. 2017. 88 f. Trabalho de Conclusão de Curso. Universidade Estadual paulista "Júlio de Mesquita Filho" Faculdade de Filosofia e Ciências - FFC, Marília, 2017.

NINA RODRIGUES, Raymundo. Os africanos no Brasil. 2010. Disponível em: http://books.scielo.org/id/mmtct/pdf/rodrigues-9788579820106-00.pdf Acesso em: 29 de Julho de 2020, 18h50.

PRADO, Antônio Arnoni. Lima Barreto: o crítico e a crise. São Paulo: Martins Fontes, 1989.

SCHWARCZ, Lilia Moritz. O espetáculo das raças: cientistas, instituições e questão racial no Brasil: 1870-1930. São Paulo: Companhia das Letras, 1993.

SÉMELIN, Jacques. Purificar e Destruir: Usos políticos dos massacres e dos genocídios. Rio de Janeiro: Difel; 2009. 
SEVCENKO, Nicolau. Literatura como missão. Tensões sociais e criação cultural na Primeira República. São Paulo: Brasiliense, 1995.

\section{ANEXO}

\section{Lima Barreto}

Quando naquele dia São Pedro despertou, despertou risonho e de bom humor. E, terminados os cuidados higiênicos da manhã, ele se foi à competente repartição celestial buscar ordens do Supremo e saber que almas chegariam na próxima leva.

Em uma mesa longa, larga e baixa, em grande livro aberto se estendia e debruçado sobre ele, todo entregue ao serviço, um guarda-livros punha em dia a escrituração das almas, de acordo com as mortes que Anjos mensageiros e noticiosos traziam de toda extensão da terra. Da pena do encarregado celeste escorriam grossas letras, e de quando em quando ele mudava a caneta para melhor talhar um outro caráter caligráfico.

Assim páginas ia ele enchendo, enfeitadas, iluminadas em os mais preciosos tipos de letras. Havia no emprego de cada um deles, uma certa razão de ser e entre si guardavam tão feliz disposição que encantava o ver uma página escrita do livro. O nome era escrito em bastardo, letra forte e larga; a filiação em gótico, tinha uma ar religioso, antigo, as faltas, em bastardo e as qualidades em ronde arabescado.

Ao entrar São Pedro, o escriturário do Eterno, voltou-se, saudou-o e, à reclamação da lista d'almas pelo Santo, ele respondeu com algum enfado (endado do ofício) que viesse à tarde buscá-la.

Aí pela tardinha, ao findar a escrita, o funcionário celeste (um velho jesuíta encanecido no tráfico de açúcar da América do Sul) tirava uma lista explicativa e entregava a São Pedro a fim de se preparar convenientemente para receber os ex-vivos no dia seguinte. 
Dessa vez ao contrário de todo o sempre, São Pedro, antes de sair, leu de antemão a lista; e essa sua leitura foi útil, pois que se a não fizesse talvez, dali em diante, para o resto das idades - quem sabe? - o Céu ficasse de todo estragado. Leu São Pedro a relação: havia muitas almas, muitas mesmo, delas todas, à vista das explicações apensas, uma lhe assanhou o espanto e a estranheza. Leu novamente. Vinha assim:

P. L. C., filho de..., neto de..., bisneto de... - Carregador, quarenta e oito anos. Casado. Casto. Honesto. Caridoso. Pobre de espírito. Ignaro. Bom como São Francisco de Assis. Virtuoso como São Bernardo e meigo como o próprio Cristo. É um justo.

Deveras, pensou o Santo Porteiro, é uma alma excepcional; com tão extraordinárias qualidades bem merecia assentar-se à direita do Eterno e lá ficar, per saecula saeculorum, gozando a glória perene de quem foi tantas vezes Santo...

- E porque não ia ? deu-Ihe vontade de perguntar ao seráfico burocrata.

- Não sei, retrucou-Ihe este. Você sabe, acrescentou, sou mandado...

- Veja bem nos assentamentos. Não vá Ter você se enganado. Procure, retrucou por sua vez o velho pescador canonizado.

Acompanhado de dolorosos rangidos da mesa, o guarda-livros foi folheando o enorme Registro, até encontrar a página própria, onde com certo esforço achou a linha adequada e com o dedo afinal apontou o assentamento e leu alto:

- P. L. C., filho de..., neto de..., bisneto de... - Carregador. Quarenta e oito anos. Casado. Honesto. Caridoso. Leal. Pobre de espírito. Ignaro. Bom como São Francisco de Assis. Virtuoso como São Bernardo e meigo como o próprio Cristo. É um justo.

Levando o dedo pela pauta horizontal e nas "Observações", deparou qualquer coisa que o fez dizer de súbito:

- Esquecia-me... Houve engano. É! Foi bom você falar. Essa alma é a de um negro. Vai para o purgatório. 
(In: Revista Souza Cruz, Rio de Janeiro, agosto de 1924)

\section{APÊNDICE - REFERÊNCIA DE NOTA DE RODAPÉ}

5. Francisco de Assis BARBOSA fez a mais extensa e rigorosa biografia sobre Lima Barreto, exatamente por ter tido amplo acesso aos diários e anotações deixados pelo escritor, além de ganhar a confiança dos irmãos - em especial, da irmã Evangelina -, que the entregaram inúmeras obras ainda inéditas e fornecerem detalhes importantes da vida pessoal do escritor. Essa proximidade com a família também permitiu que pudesse entrevistar amigos que conviveram com o escritor. A vida de Lima Barreto, 2012.

Enviado: Setembro, 2020.

Aprovado: Setembro, 2020. 